\title{
Under the Tourist Gaze: Kathmandu in Popular Culture*
}

\author{
Arvind Dahal \\ Lecturer of English \\ Saraswati Multiple Campus, Kathmandu \\ dahalarvind@gmail.com
}

\begin{abstract}
This research explores the shifts and continuities of representing Kathmandu City in Western cinematic and musical creations since 1970s. My research concerns with the representations of Kathmandu in the popular culture intends to explore the imagination of Kathmandu as a touristic place and how they represent the city and produce images in the popular culture which expands far beyond the visual apprehension and enjoyment of a landscape. While doing so my research first explores the representations, practices and processes of identity formation and cultural negotiations that are brought about in the city by tourism and secondly, it analyses the content and the visual representations of the movies and songs relying primarily on the theoretical tools of Popular Culture and secondarily the image production of the landscape in terms of Tourist gaze.
\end{abstract}

Keywords: Cultural politics, duplicity of landscape, Gaze, psychedelic orientalism, staged authenticity.

\section{Kathmandu in Popular Culture}

The popular culture dating back to 1970s and now represent Kathmandu City metaphorically in two basic concepts. One, that of a body and other that of a prelapsarian Eden, a Hindu and a Buddhist remnant. Those artistic creations which revolve around Kathmandu sustain and reinforce such representation by describing Kathmandu as ancient land of trippy gurus and monks holding secret psychedelic wisdom that could liberate the young hippie from the system of stuffy bourgeois western values. There is of course no ethnographic basis to that view. Western philosophers, intellectuals and musicians resent the association with drugs but mystical and psychedelic Kathmandu is still the powerful symbol in their creations nevertheless.

* Received: March 11, 2020

Peer Reviewed: July 3, 2020

Accepted: September 2, 2020 
This exotic representation of Kathmandu helped tourism in several ways. Kathmandu has had a thriving tourist industry since the 70's first in the form of the Hippies seeking an authentic spiritual experience and second their children who still see this city from the same perspective as that of their parents. John Urry, in his seminal book Tourist Gaze (1990), believes places are chosen to be gazed upon because there is anticipation, especially through daydreaming and fantasy. Such anticipation is constructed and sustained through a variety of non-tourist practices, such as film and TV which construct and reinforce that gaze. Furthermore a term closely linked with the tourist gaze is the 'photographic gaze' which is often referred to capturing the moment of one's experience and according to Urry is the most important tourist activity within Film Induced Tourism.

A mystic Oriental gaze of Kathmandu in the popular songs and motion pictures held sway since 1970s. Bob Segar's "Katmandu" (1973) was one of the earliest and most potent manifestations of "psychedelic orientalism" within rock music. Similarly, Cat Steven's "Oh Katmandu”(1975), Janis Joplin's “Cry Baby”(1977), John Lennon's "Nobody Told Me” (1979), and Jim Morrison's "Roadhouse Blues"(1974) reveal that the visual gaze renders extraordinary, activities that otherwise would be mundane and every day. The attraction towards Kathmandu is not the object of attraction itself but the sign referring to it that marks it out as distinctive. All these songs have a common thread in itself that Kathmandu appears in them in the form of covert day-dreaming and anticipation are processes central to modern consumerism. Content analysis of these songs in a historical and cultural context will uncover dynamics of tourist gaze, themes of appropriation and cultural hegemony in the artistic creations when it comes to representing a city space in the following sections.

The songs selected for the research were written by young musicians who came of age during the last days of the British Empire and the heydays of American Imperialism, and in writing them they were enacting a musical relationship with their unsanctioned former colony. The musicians who are referring Kathmandu in the sense of satisfaction to consume it through music are likely to stem from anticipation, from imaginative pleasure seeking as a touristic gaze. A close analytical look at these songs and content analysis of the scenes which represent Kathmandu in Hollywood motion pictures like To the North of Kathmandu (1986), Witch from Nepal (1988), The Golden Child (1991), Little Buddha (1991), A Night Train to Kathmandu (1994), There's Something About Mary (1998), Doctor Strange (2016) portray the landscape of Kathmandu having a cornucopia of images of medieval cities and sacred sites.

Nepal is represented as a refined place, admiring the peaks over a gin and tonic from a Himalayan viewpoint, strolling through the medieval city squares of Kathmandu, Patan and Bhaktapur, and joining Tibetan Buddhist pilgrims on a spiritual stroll around centuries-old stupas and monasteries. Some movies also show the stone-flagged Durbar square, possessed 
ascetics and mystics, barelegged, cracked bare feet, calloused thick stubby toed poor people as well. Other bizarre representations include the mica filled water of Kathmandu which gives everyone runs. Kathmandu as a Mecca for Hashish lovers is the most dominant representation of the city. It has also been gazed upon metaphorically as a Hindu and Buddhist remnant which stands alongside the prelapsarian Eden, an image of a utopian place which lingers in the western mind till now. The research is an attempt to uncover the politics of gaze which metaphorizes the city and as a result the tourism industry is flourished.

The research argues that Kathmandu is represented in Western popular culture as a welcoming place, a last resort even to the wayward sons, superfluous populations of delinquents, poor people, other undesirables, and an escapade for the hashish lovers. Nonwestern critics argue that it is done deliberately to exert colonial and puritan legacy. But, on the contrary, they are discrediting the paradigm shifts and positive repercussions brought about by those representations. They argue that the representations show the lingering colonial mentality in the sense that they still consider Kathmandu as a mystic oriental place and Puritan in the sense that Americans still have few ideas about the holiness of poverty. They square that the representation of Kathmandu in popular songs and motion pictures of Hollywood is problematic because it always tends to present Kathmandu having an exotic image of a mystical place and discredits the modern paradigm shift or thought process of this city.

But on the other hand the exotic images of the city draw tourists for the search of an authentic experience of living in a mystical place. For them Bob Segar's "Kathmandu" (1972) is an overtly exaggerated song. Bob Segar makes the location sound like a drunken debauchery and lasciviousness. Similarly, other popular songs and motion pictures also pontificates Kathmandu as a mythical, possessed and a poor city. This dominant representational paradigm indicates that their approach offers a very unreal representation of Kathmandu. It is represented like this by the choice of the lyricist, the script writer as well as the cinematographer and the producers too because Kathmandu (the Orient) needs investigation; the West has knowledge and produces knowledge, and the Orient is raw data waiting to be shaped into knowledge. The Oriental lacks knowledge of himself, and needs it, and can only obtain it from the structuring Western mind. But, we cannot ignore the fact that such representations have, since early $70 \mathrm{~s}$, proven to be extremely popular till today. Recent release Doctor Strange (2016) presents Kathmandu as the residence of mystic monks having capacity to cast spell worldwide. The post-colonial thinkers argue that this knowledge must be contested and the attitude of power that characterizes the West must be debunked.

\section{Review of Literature}

The gaze of Kathmandu by the Western popular culture advances the view that it appropriates and displays knowledge for certain ends. It is incorporated and constructed by the 
articulation of pre-existing discourses. The West becomes the arbiter of meaning since its institutional position allows it to articulate and reinforce the scientific credibility of frameworks of knowledge or discursive formations through its methods of display. This geopolitics allows Kathmandu to be subjected to the scrutiny of power. This derives also from a historically unequal relationship between western powers and the other. The emergent 'performative approach' to tourism and the importance of 'the sensual' in tourist experience is also central to David Crouch's work, Visual Culture and Tourism (2003). Crouch welcomes the focus on 'doing' brought about in cultural studies by key scholars such as Edensor, and theorized by 'non-representational' theory, which lays emphasis on the everyday aspects of living, on what individuals do in their ordinary life. Crouch suggests that following the direction pointed out by Edensor and the non-representational approach, new research in cultural studies and tourism should aim at making sense of meaning, value, significance and identity engaged in the experience of travel through greater attention to what individuals do, think, and feel.

The term "gaze" refers to the discourses and practices of seeing in tourism contexts as well as to ways of knowing what is being looked at. Originally framed by Michel Foucault's notion of discourse, the prison and the medical gaze, it is now concentrated on tourist systems, institutions, and visitor economy. Subsequently, "gazing" came to encompass an interpretive idea, thereby prompting theorists to also examine host and guest behaviors. Urry was the first to mention that there were systematic ways of "seeing" destinations, "which had roots in Western ocular centric practices" (32), essential to debates that enveloped modernity.

Situated in the Himalayas, Nepal is a place of ancient architecture and stunning vistas, as well as an area of great importance to the Buddhist faith. It has had a thriving tourist industry since the 1950s, when it became more readily accessible by plane. Throughout the 1960s and 70s, Kathmandu, the capital of Nepal was a popular destination for hippies seeking an "authentic" spiritual experience, so much so that the Jhochen Tol neighborhood is still known by many today as Freak Street:

Freak Street is a small street located at the south of Kathmandu Durbar Square which refers to the ancient Hippie trail of the 1960s and 70s. The Hippies, the Rastafaris, the flower children searching for happiness and Nirvana, all arrived in their Mercedes Benz. They converted the pig alley to Pie Alley and Swoyambhu to Monkey Temple. Freak Street saw the regular Hare Krishna to the infamous Charles Sobraj. (Pietri 31)

This ancient street which was named Freak Street, after the hippies, presently the name Freak Street is changed into Old Freak Street since the place is not anymore like it used to be in the $60 \mathrm{~s}$ and $70 \mathrm{~s}$. 
This place is now just a mythical magnet for hippies and other social variants of the 1960s. Those days are long gone, but the popular culture from 1970s till today represents Kathmandu as the Mecca for Hashish lovers. The Kathmandu valley has been referred as the "Emerald Valley" (Subedi 12). Numerous works of literature have been set in Kathmandu, including Kim Stanly Robinson's 1989 work, Escape from Kathmandu, Kurt Vonnegut's novel Deadeye Dick (1990) whose protagonist Rudy Waltz writes a play titled Kathmandu in which a man takes a journey on foot to Kathmandu. All these writings including one of the comic series of Tintin titled, Tintin in Tibet (2004) whose characters land in Kathmandu and spend some time in the city before heading towards Tibet, a video game titled "Uncharted 2" by Naughty Dog for the PlayStation 3, includes several chapters in Kathmandu, in a game named "Civilization", Kathmandu appears as a city-state which the more powerful civilizations can interact with.

All these works has a common thread and that is it mystifies Kathmandu:

Myth sees in them the same raw material; their unity is that they all come down to the status of mere language. Whether it deals with alphabetical or pictorial writing, myth wants to see them only a sum of signs, a global sign, and the final term of the global semiological chain. And it is precisely this final term which will become the first term of the greater system which it builds and of which it is only a part. (Hall 68)

In popular imaginaries, "world cinema" and Hollywood commercial cinema appear to be two opposing forms of filmic production obeying diverse political and aesthetic laws. However, definitions of world cinema have been vague and often contradictory, while some leftist discourses have a simplistic take on the evils of reactionary Hollywood, seeing it in rather monolithic terms. Such monolithic ideas diagnose that Kathmandu is represented as a mystic place by the choice of the lyricist, the script writer as well as the cinematographer and the producers too because Kathmandu (the Orient) needs investigation; the West has knowledge and produces knowledge, and the Orient is raw data waiting to be shaped into knowledge. The Oriental lacks knowledge of himself, and needs it, and can only obtain it from the structuring Western mind. We cannot ignore the fact that such representations have, since early 70 s, proven to be extremely popular till today.

\section{Problems, Objectives and Methodology}

Popular culture critic Melissa Brown argues that the Film Induced Tourism has become a main feature on the calendar of popular culture in recent years. Film Tourism, informally known as "set jetting" (Brown 2) is where travelers visit the locations of popular films and has been identified by Travel Mole as a growth area for tourism. My research shows that the tourist gaze is often directed by anticipation and imagination, by the promotional narratives of the tourism industry, by cultural stereotypes and ones expectations. According to Hudson and 
Ritchie, film tourism is defined as how, "tourist visits to a destination or attraction as a result of the destination being featured on television, video, or the cinema screen" (9). Film tourism is a growing phenomenon worldwide, fueled by both the growth of the entertainment industry and the increase in international travel, and in addition research shows the main motive for this type of holiday is purely for entertainment and enjoyment and therefore for some, may provide a sense of excitement or a thrill. Important features of this particular type of holiday to some include the aspect of reality. In addition, Margaret Hodge, Minister for Film and Tourism of UK states that people seek to relive their favourite movie moments:

Of course, it is often argued that the majority of the locations and special sites only become popular tourist appeals because of the film created on site. Riley and Van Doren and Macionis $\mathrm{N}$ argues that although it is recognized that films are not produced with the purpose of inducing tourism visitation, it is commonly accepted that feature films, seen by mass audiences, can indeed enhance the awareness of the locations in the film, as well as the appeal of these tourist destinations. BBC News gave evidence of this with Harry Potter, The Da Vinci Code and TV series Pride and Prejudice which identified an increased visitation to those production setting locations. (8)

In addition, Hall introduces the aspect of authenticity within Film Tourism. He states that authenticity is one of the key motivational factors for tourists and film tourism, for instance, is one medium that allows people to live out their fantasies of their favorite movies or actors in sometimes mythical places. Furthermore researchers believe that authenticity, existential authenticity, sincerity, hyper-reality and simulacra are all overlapping concepts often used in accounting for the tourist experience.

The aspect of 'on-location' and 'off-location' determines whether such sites become very much inauthentic. According to Beeton S, in terms of 'authenticity', on-location sites are not necessarily authentic, in that many places are filmed in such a way that they appear quite different from 'real life', or may even be presented as a completely different site. The term offlocation, relates to filming undertaken in a set constructed within the confines of the production unit, away from a naturally-occurring setting such as a town, coastal area or desert, and at first glance may be considered to be totally in-authentic, yet for the post-tourists, are quite 'real'. In contrast to MacCannell, who believes that tourists desire authenticity, Urry, argues that tourists understand that it is impossible to have an authentic tourist experience and in fact enjoy inauthentic activities.

Inducement for this particular type of tourism is often closely in conjunction with tourism motivation. Dann proposes that there are two stages in one's decision to travel: push factors and pull factors. Researchers often refer to the push factors as the needs and the wants of the traveller and are therefore the reasons why people want to escape from their normal habitat. 
Pull factors are referred to the motives for visiting certain destinations. Macionis furthers this by stating that it is anticipated that there are a diverse range of push factors associated with visiting film sites including fantasy, escape, status and prestige, search for self-concept or identity, ego enhancement, as well as a sense of partaking in a vicarious experience. He also argues, people are not only drawn to the places that form the settings and landscapes for feature films, but they may also be drawn to particular stories and genres, that is the drama of the plot, elements of the theme and experiences of the people in the film.

A critical internal driver, or push motivation in film induced tourism is the 'tourist gaze' in terms of film, constructing a gaze for an individual to observe. Research shows the gaze is often directed by anticipation and imagination, by the promotional narratives of the tourism industry, by cultural stereotypes and ones expectations. Urry believes places are chosen to be gazed upon because there is anticipation, especially through daydreaming and fantasy. Such anticipation is constructed and sustained through a variety of non-tourist practices, such as film and TV which construct and reinforce that gaze. Furthermore a term closely linked with the tourist gaze is the 'photographic gaze' which is often referred to capturing the moment of one's experience and according to Urry is the most important tourist activity within Film Induced Tourism:

Authenticity in tourism is linked to MacCannell's notion of "staged authenticity", where "frontstages" are staged to create a sense of authenticity. This has meant that there is a rise in these commodified sites, which can be linked to film tourism. According to the post-modern tourism, the notion of authenticity is less important, and that they don't mind that their experience is a reproduction of something else. A postmodern tourist often knows that it's almost impossible to get an absolute authentic experience, and know that it's not possible to go back in time to where an item or object was from, which further proves it's almost impossible to get an absolute authentic experience. (Urry 57)

The possibility of linking staged authenticity together to film tourism in matters of authentic experience is in a way very challenging, and it's also important to remember that the tourists have a knowledge that the sites they visit due to a film is in fact fiction, which means they realize they won't get a complete authentic experience. Film tourism is also linked to hyperreality, where a model and reality are confused. The film tourist has as Urry states have learned to accept hyper-real experiences, instead of an authentic experience.

\section{Representations of Kathmandu in Popular Culture}

The representation of Kathmandu City from its very beginning is a profoundly gendered symbol, a metaphor of the female body. The popular culture metaphorizes Kathmandu City in basically two concepts: one that of body and the other that of prelapsarian Eden and Hindu or 
Buddhist remnants. A city can be seduced and conquered, and it can also, conversely, appear in terms of a seductive figure: the image of a mysterious, alluring female figure, appealing yet disconcerting. Even saints such as Augustine and Jerome confessed to having been "allured and teased by sensuous images of Rome" (Urry 74). The type of voyeurism built into viewing film and particularly films that have oriental outdoor locations means that there are many links between tourism (in terms of travel abroad) and film spectatorship. A number of theorists have commented on the links between the viewing process of the tourist and the film spectator. Tourist gaze includes practices beyond traditionally conceived concepts of tourism, and this gaze as central to cinema and television viewing, anthropological study.

Bob Segar's "Katmandu" (1973) is one of the earliest and most potent manifestations of "psychedelic orientalism" within rock music. The overtly exaggerated "K-k-k-Kathmandu" by Bob Segar makes the location sound like a drunken debauchery and lasciviousness:

That's where I am going to Katmandu

Up to the mountains where I am going to

If I ever got out of here

That's what I am gonna do

I raise my whiskey glass, and give 'em a toast,

Kkkkkk, Katmandu (11. 10-15)

Segar presents Kathmandu as a remote and exotic location. The city for him is a prelapserian Eden which he anticipates to go. He took a humorous tone, singing about the desire to disappear for a while far away (Kathmandu) where no one will bother you. Segar used alternate spelling of Kathmandu as 'Katmandu' which made it easier for the western eyes to comprehend. Segar's 'Katmandu' is his anticipation as a tourist for a 'floating', unstable gaze enriched with a sensorial and emotional immersion in the landscape. Fixed-and-frozen representations are set in motion by the physicalities of the drug induced intoxication. The rock music and overtly exaggerated tone, the enfolding misty landscape of Kathmandu is his anticipation for new adventures to be experienced, either on the visual world of drugs or also on the real world.

Segar's Kathmandu is his anticipation as a tourist for a 'floating', unstable gaze enriched with a sensorial and emotional immersion in the landscape. Fixed-and-frozen representations are set in motion by the physicalities of the drug induced intoxication. The rock music and overtly exaggerated tone, the enfolding misty landscape of Kathmandu is his anticipation for new adventures to be experienced, either on the visual world of drugs or also on the real world.

Apparently, even the yearning for peace and tranquility is transmuted into ass-kicking rock and roll within the mind of Bob Seger. The growling vocals and honk-tonk piano of 
Seger's "Katmandu" make the location sound like a city of drunken debauchery and lasciviousness. While air-guitaring around the living and kicking over imaginary amps, one can very easily overlook the fact that Kathmandu is a real place, and it is the capital of Nepal, which is the birthplace of Gautama Buddha and one of the modern centers of Buddhism. In short, Kathmandu is not actually a particularly raucous party town. It is clear, going by the lyrics, that Seger was perfectly cognizant of where and what the real Kathmandu is. In the song, he's talking about how he's fed up with the hectic pace of American life. He assures us that he loves all the regions of his native country, but that he's not feeling happy anymore. He wants to escape into the tranquility of the Nepalese mountains to be true to himself and stop "being blue."

Kathmandu City is from its very beginnings a profoundly gendered symbol, something which will be discussed later in relation to the figure of the flaneur and flaneuse. The city can be seduced and conquered, and it can also, conversely, appear in terms of a seductive figure: the image of a mysterious, alluring female figure, appealing yet disconcerting. Even saints such as Augustine and Jerome confessed to having been "allured and teased by sensuous images of Rome" (Urry, 74). The type of voyeurism built into viewing film and particularly films that have oriental outdoor locations means that there are many links between tourism (in terms of travel abroad) and film spectatorship.

"Nobody Told Me" song was released more than two years after Lennon was killed and, was released in the album Milk and Honey in 1984. The song was written in 1969 when Lennon connected himself with the hippie nomadity. The song contains the message of new age spirituality, destruction of racial boundaries, hallucinogenic, free love, war and non-conformity which comprises of all the themes of counterculture. This song is a protest song which is in different league among all drug related songs for its opulent metaphors and the musical crafting of words:

Everybody's talking and no one says a word

Everybody's making love and no one really cares

There's Nazis in the bathroom just below the stairs

Always something happening and nothing goin on

There's always something cooking and nothing in the pot

They are starving back in China so finish what you got. (11. 1-6)

Besides subverting the sexual patterns of conventional America, even more controversial and challenging during the time was a liberal view of drug use. The hallucinatory factors got into mind of the hippies who used to tale cannabis and LSD. There is always something happening and nothing going on gives the visual image of a person in trance. While images of Nazi's or crossing boundaries like going to China in the song shows the celebration of hippie nomadity. 
The celebration of free sex was notorious of the countercultural era. Lennon mentions in the song that everybody is making love and no one really cares which implies to the point of celebration of free sex. Lennon further uses various images of hippie nomadity in the song:

Everybody's running and no one makes a move Everybody's a winner and nothing left to loose There is a little yellow idol in the north of Kathmandu Everybody's flying and no one leaves the ground. (11. 11-14)

Drugs were considered by the hippies as such substances which expanded the mind to new realms of experience and as vital aids to personal and thereby social transformation. The hippies took recourse to eastern religiosity and wandered around places where drugs were free. Kathmandu was famous at the countercultural era as a place where drugs were free and cheap and, various places where the hippies could expand their minds. Lennon has referred the "little yellow idol in the north of Kathmandu" (13) which he is referring to Vajra Yogini temple near Sakhu, John Lennon's song "Nobody Told Me" refers to "a little yellow idol to the north of Kathmandu" which indicates his fascination to Buddhism and Tantra because of its reference to "Bajra Yogini" of Sankhu as researched by a BBC television reporter Joanna Jolly in her programme "From Our Own Correspondent" (Mitchell 42- 43). Getting high on narcotics, living the present fully and putting aside the future was the lifestyle of the counterculture followers and the song celebrates the very essence.

The lead singer of The Doors, Jim Morrison's 1972 hit "Roadhouse Blues" is a euphoric blues number which talks about a countercultural reaction where many Americans were against the United States' involvement in the Vietnam War and spoke out against it. Artists, as well as citizens choose to clearly denounce the war:

Yeah, keep your eyes on the road, your hand upon the wheel

Keep your eyes on the road, your hands upon the wheel

Yeah, we're goin' to the Roadhouse

We're gonna have a real

Good time

Yeah, back at the Roadhouse they got some bungalows

Yeah, back at the Roadhouse they got some bungalows

And that's for the people

Who like to go down slow (11. 1-9)

When Jim Morrison got drunk, he liked to sing blues numbers at The Doors jam sessions. This is one of the songs he came up with at one of those inebriated sessions. If there was an actual roadhouse that inspired this song, it was the Topanga Corral, a windowless nightclub in 
the counterculture enclave of the Topanga Canyon, where Jim Morrison lived. The reason for choosing this song for the research is because Morrison's anticipation to come to Nepal to consume "Ganja" is evident from the fact that he utters Nepali words in the middle of the song. He was also infamously called "The Lizard King" (Pietri 90), for he was endorsing the surreal effect of intoxication induced by smoking the lizard tail.

Exact words said by Jim Morrison in the song "Roadhouse Blues":

Ganja chucha [Let's smoke weed]

khau khau khau [Smoke smoke smoke]

Hookah Ganja [Hookah filled with weed]

Hei cha koona mai cha [Growing right on the corner too]

Pa Paru rai cha [Growing over there]

ooh wha pani cha [Right next to it too]

Hein cha [Its everywhere]

Khau khau khau [Let's smoke smoke smoke] (11. 18-25)

Nepalese would say it: "Ganja chusa/ khau khau khau/ Hookah Ganja/ Hei cha koona mai cha/ ooh pari pani cha/ ooh wha pani cha/ hein cha/ khau khau khau". The words get translated into the following word meaning: Ganja as Weed, chusa is sucking action of smoke from pipe of hookah, khau is let's eat (no word in Nepali for verb "smoke" so we use verb "eat" for smoke, although there's a word for noun "smoke" it's called "dhuwa" noun ), Hookah Ganja is Hookah filled with Weed, Hei cha is its growing right here, koona mai cha is its growing right in that corner too, ooh pari pani cha is it's also growing over there, ooh wha pani cha is and then it right next to it too, hein cha khau is its everywhere, lets smoke (italki 1). Now we can imagine why this song is so euphoric, his touristic gaze transforms into surreal and romantic gaze for Nepal and he is assured he can smoke weed in a freaky way in Nepal(during the hippie era, not legal now). So, Kathmandu for the Hippies and the Freaks in the countercultural era was a metaphoric Eden. In the 70s, many Americans were fascinated with Eastern orthodoxy and saw places like Kathmandu as beacons of enlightenment. Many young people made the trek, and some high-profile musicians mentioned the city in songs where it was used as a metaphoric Eden, which is what Cat Stevens did in "Oh Kathmandu" (1974) as he sings about finding refuge from Western civilization in a simpler, peaceful place:

I sit beside the dark

Beneath the mire

Cold gray dusty day

The morning lake

Drinks up the sky

Katmandu I'll soon be seeing you 


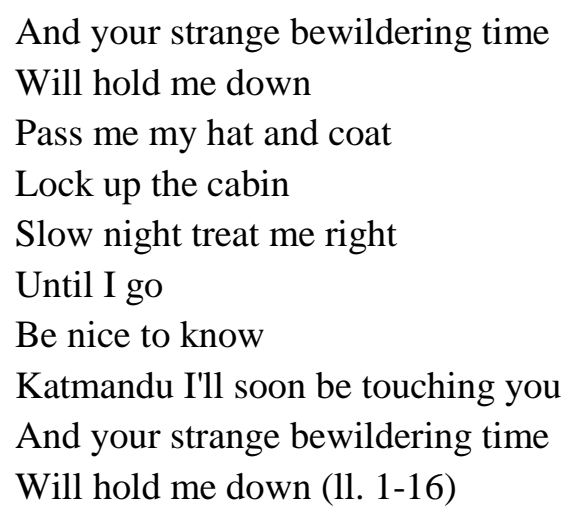

There are plenty of reports claiming that Stevens wrote this song in Kathmandu. Karna Shakya remembers that he heard rumors that Stevens wrote it in a tea house in the Jhoche Tole section, "There were lots of rumors about Stevens writing 'Katmandu' at Eden Hotel a hashish joint in Freak Street", but there is no evidence that he made this journey. Stevens was certainly there in spirit, however, as Bob Seger would be in 1972 when he released his own song about Kathmandu, also spelled without the ' $h$ ' just like Bob Segar.

Chop me some broken wood

We'll start a fire

White warm light the dawn

And help me see

Old Satan's tree

Katmandu I'll soon be touching you

And your strange bewildering time

Will keep me home (11. 17-24)

Cat Stevens is referring to the cannabis plant when he makes reference to satan's tree. In chapter 3 of Genesis, "the tree of knowledge of good and evil" (3:1-3) is described there. One of its attributes is giving one insight and wisdom. In the lyrics of Katmandu, it is stated "help me see, o satan's tree" (20-21). Nepal was the last place on earth to make cannabis illegal. Royal Nepalese hashish was a major national product in Nepal. Also Lord Shiva the Lord Protector of Nepal consumed it. One of his favorite pastimes was smoking cannabis on Mount Kailash. The holy men that are his followers, sit on the Bagmati River smoking cannabis and chant "dum muro dum, mit jay gum, aloh subah sham, Hare Krishna, Hare Ram [you smoke and smoke, your mind is in Cosmic consciousness, you always see reality]" (my translation) (Anand 59 mins] very deep in a very deep place. That is why all the hippies traveled there. Similarly, Janice Joplin's “Cry Baby” (1974) metaphorizes Kathmandu as a prelapsarian Eden: 
And when you walk around the world, babe,

You said you'd try to look for the end of the road,

You might find out later that the road'll end in Detroit,

Honey, the road'll even end in Kathmandu.

You can go all around the world

Trying to find something to do with your life, baby,

When you only gotta do one thing well,

You only gotta do one thing well to make it in this world, babe.

You got a woman waiting for you there,

All you ever gotta do is be a good man one time to one woman

And that'll be the end of the road, babe,

I know you got more tears to share, babe,

So come on, come on, come on, come on, come on,

And cry, cry baby, cry baby, cry baby. (11. 21-34)

"Cry Baby" revolves around a woman who's telling her true love who left her, that if he ever needed someone to love, or ever anything, that she would always be there waiting for him. All he has to do is ask. It's about selfless love which she claims to find only in Kathmandu.

I now examine the ways in which the film engages with the tourist gaze and ask whether the film replaces this gaze with a world cinema gaze or merely reproduces it in new ways. Hollywood motion pictures like, Witch from Nepal (1988), The Golden Child (1991), A Night Train to Kathmandu (1994), Baraka (2000), and Doctor Strange (2016) portray the landscape of Kathmandu having a cornucopia of images of medieval cities and sacred sites. Nepal is represented as a more refined place, admiring the peaks over a gin and tonic from a Himalayan viewpoint, strolling through the medieval city squares of Kathmandu, Patan and Bhaktapur, and joining Tibetan Buddhist pilgrims on a spiritual stroll around centuries-old stupas and monasteries.

The Golden Child is a 1986 motion picture which metaphorizes Kathmandu as a Hindu and a Buddhist remnant. In a temple in an unknown location in northeastern Nepal, a young boy with mystical abilities the golden child receives badges of station and demonstrates his power to the monks of the temple by reviving a dead eastern rosella, which becomes a constant companion. The images of Boudhanath and Swayambhu is often displayed and featured when the Golden Child has a footage in the screen. The images of the Hindu temples and the Buddhist Monasteries are gazed upon as a mysterious and mythical.

Baraka (1992) is a non-narrative film directed by Ron Fricke. The film opens in Nepal at the Bhaktapur Durbar Square and moves to and fro between Boudhanath, Hanuman Ghat, Pashupati Nath and Swayambhunath. Without words the cameras show the world "what's 
there in Kathmandu?". Kathmandu wakes up with people (Newars) performing their daily chores and ascetics and monks worshiping with their holy beads. Baraka is an ancient Sufi word, which can be translated "as a blessing, or the breath, or the essence of life from which the evolutionary process unfolds" (Beeton 31). In The Night Train to Kathmandu (1988), Lily is forced to leave Princeton, and with her parents and brother she travels to Nepal. She is unhappy for she had to leave her own country and her old life behind to visit this mystic country with her family. Once there, however, she meets a mysterious Nepalese Shakya Prince named Joharv and falls in love with him and the country. Joharv leads Lily as well as her brother and her anthropologist father to search for the legendary invisible "City That Never Was" against the backdrop of the Himalayas. Kathmandu City is gazed upon as an invisible city which is idyllic and can be seen by those who have a pure soul. I want to relate this notion as similar to Italo Calvino's notions about cities in his seminal book Invisible Cities (1972). Italo Calvino illustrated the seemingly ineffable aspects of urban developments by portraying a series of imaginary "cities." Elevated to the realm of the fantastical, these cities are conceived as more than just physical structures but a confluence of ideas and emotions: the built crossroads of multitudinous lives. Scholars studying the literary city can be roughly divided into two groups, with the extreme sides of the axis insisting on either a direct relation between the "actual" and "fictional" city, or treating the literary city as a completely independent world. Urry calls these opposing poles respectively "formalists" and "historicists" and insists that, despite heated debates, "the study of the city and its art is not a matter of 'either/or', of embracing one approach to the exclusion of others" (76). Tourists gaze upon a city with their occupied notion about the city rather than discover which it really stands for.

In Witch from Nepal (1986) while on vacation in Nepal, Joe Wong (Chow Yun-fat) and his girlfriend, Ida (Yammie Lam), ride an elephant when Joe falls and hurts his knee and is sent to a hospital. In a local hospital, Joe has visions of a beautiful veiled woman with mystical powers. The 2016 movie Doctor Strange starts in Kathmandu, Nepal, the sorcerer Kaecilius and his zealots enter the secret compound Kamar-Taj and behead its librarian. They steal a ritual from an ancient and mystical text belonging to the Ancient One, a long-lived sorcerer who has taught every student at Kamar-Taj, including Kaecilius, in the mystic arts learned from the ascetics of Kathmandu.

What emerges from the discussion of my finding is that tourists are, in a way, semioticians reading the landscape for signifiers of certain pre-established notions or signs derived from various discourses of travel and tourism. Their practices enact different gazes, where the social actors involved negotiate different imageries, imagined landscapes, understandings of self and other. Indeed, tourist practices are to be thought of as practices of identity which dynamically engage with dominant narratives and individual imaginations, with the global patterns of the tourism industry and personal trajectories, with fantasies, dreams, 
expectations, and materialities, objects, bodies, with the aesthetic and the lived landscape. These areas are defined both by the imaginative geographies endorsed by the Popular Culture and by the repetition of practices and the corporeal engagement of tourists with the city. So for example the Freak Street and Thamel are criss-crossed by the reiterated movements of walking. The latter is identified as a space of sensual confusion and chaos and the former serves as the headquarters for the regulated activities of organized tourism. Freak Street is the mandatory stop in the pre-designed itineraries of package tours which is also endorsed by Popular Culture.

However, what also emerged from the research is that the cartographies which are represented by Popular Culture are actually unstable and shifting. They are indeed challenged by the practices of the wandering tourist, who disobeys the official cartographies of tourism and makes connections, creates networks and spaces off the map. These unreal representations are sometimes the 'grey zones' of tourism in Kathmandu which is far removed from the guided tourism service that the city provides. But, places are chosen to be gazed upon because there is an anticipation, especially through day-dreaming and fantasy, of intense pleasures, either on a different scale or involving different senses from those customarily encountered. Such anticipation is constructed and sustained through a variety of non-tourist practices, such as film, newspapers, TV, magazines, internet, records and videos from Popular Culture which construct that gaze. Such practices provide the signs in terms of which the holiday experiences are understood, so that what is then seen is interpreted in terms of these pre-given categories. The gaze is directed to features of landscape and townscape which separate them off from every day and routine experiences. Such aspects are viewed because they are taken to be in some sense out-of-the-ordinary. The viewing of such tourist sites often involves different forms of social patterning, with a much greater sensitivity to visual elements of landscape or townscape than is normally found in everyday life. People linger over such a gaze which is then visually objectified or captured through photographs, postcards, films, models and so on. These enable the gaze to be endlessly reproduced, recaptured and practiced. Diverse aspects of the tourist gaze has been highlighted and diagnosed that the gaze can take several forms, the two main ones being the romantic and the collective. This distinction relates to the kinds of organization that the tourist industry develops to meet these different gazes. The 'romantic gaze' prioritizes solitude, privacy and a sort of spiritual relationship with the object of the gaze. Natural landscapes and sceneries of 'untouched beauty' are usually the favorite objects of the romantic gaze, which Urry believes to be an inherently bourgeois attitude. On the contrary, the 'collective gaze' demands the presence of large numbers of people who confer atmosphere and liveliness to a place. The musicians who are referring Kathmandu in the sense of satisfaction to consume it through music are likely to stem from anticipation, from imaginative pleasure seeking as a touristic gaze. 


\section{Conclusion}

The findings discussed above draw on, and contribute to, the wider academic debate on the tourist practice. This study argues that from 1970 onwards, the Popular Cultural representation of Kathmandu was approached from a surprisingly rich variety of generic and thematic perspectives which were in close dialogue with international contemporary traditions and age-old images of the city, and defined by events typical which became Kathmandu's own modern history. This resulted in fascinating and varied experiences of the city that set the tone for later creative productions. The city experience was increasingly aestheticized and internalized, and as the description of the city moved inwards, the experience of Kathmandu geared the tourist industry. While the equation of the city with the body politic reveals some of the profoundly pessimistic world views that were attributed to the urban environment, it is a metaphorization that has a more positive repercussions in terms of tourism. The fascination with the city is tied to its potential to symbolize abstract concepts that lay beyond the city boundaries the intangible concepts of community, citizenship, or the nation state. We should think of landscape as the poetics and the expression of our encounter with the world. It is perhaps in this 'poetic encounter' with the world, where representation and embodied experience come together, that the constitutive paradoxes of the tourist landscape.

However, investigations on the practices and embodied performances of tourism leave scope for further research. In fact, despite recent tourism research under the inducement of cinema and music which focuses on the body of the tourist we still know little about whose body it is. Broadening empirical research is important as it reduces the risk of constructing homogenous representations of the body of the tourist, as if the practices, feelings, affects and performances of, say, children and adult tourists, able-bodied and disabled tourists, male and female tourists, and so forth could all be gathered and represented under a uniform idea of body and perceptions.

\section{Works Cited}

Ameel, Lieven. Moved By The City: Experiences of the Helsinki in Finnish Prose Fiction 1889-1941. Diss. University of Helsinki, 2013.

Anand, Dev, dir. Hare Rama Hare Krishna. Perf. Anand and Jeenat Aman. Navketan, 1971. “Azlyrics on Bob Segar”. Bob Segar Songs. 1 Dec. 2016. <http://www.azlyrics.com/bobsegar/>

"Azlyrics on Cat Stevens". Cat Stevens Songs. 1 Dec. 2016. $<$ http://www.azlyrics.com/catstevens/>

“Azlyrics on Janis Joplin”. Janis Joplin Songs. 1 Dec. 2016. <http://www.azlyrics.com/Janis Joplin/>

“Azlyrics on John Lennon”. John Lennon Songs. 1 Dec. 2016. $<$ http://www.azlyrics.com/johnlennon/> 
“Azlyrics on Jim Morrison”. Jim Morrison Songs. 1 Dec. 2016. <http://www.azlyrics.com/Jim Morrison/>

Baraka. Fricke Ron. The Samuel Goldwyn Company, 1992. dvd.

Beeton, Sue. Travel, Tourism and the Moving Image. Channel View Publications, 2015.

- - -. Film Induced Tourism. Channel View Publication, 2005.

Bellman, Beryl L. Taboo: Time and Belief in Exotica. Sage, 2008.

Benjamin, Walter. The Work of Art in the Age of Mechanical Reproduction. Harcourt, 2007.

Barker, Chris. Making Sense of Cultural Studies: Central Problems and Critical Debates. Sage, 2002.

Baudelaire, Charles. Le Peintre de la Vie Moderne, Paris. Harvey Press, 1861.

Brown, Mellissa. Cultural Heritage Politics in China. Springer, 2000.

Calvino, Italo. Invisible Cities. Giulio Einaudi, 1974.

Crouch, David. Visual Culture and Tourism. Hartcourt, 1990.

Cosgrove, David. Social Formation and Symbolic Landscape. Croom Helm, 1984.

Culler, John. "Semiotics of Tourism." American Journal of Semiotics, vol. 1, 1981.

Dennison, Stephanie and Song Hwee Lim. Remapping World Cinema: Identity, Culture, and Politics in Film. Columbia UP, 2006.

DeRogatis, Jim. Musically and Verbally Prolific. Hartcourt. 2014.

Doctor Strange. Derrickson Scott. Walt Disney Studios Motion Pictures, 2016.

Hall, Stuart. Representation: Cultural Representations and Signifying Practices. Sage, 1997.

Harvey, David. The Social Construction of Space and Time in Justice, Nature and the

Geography of Difference. Blackwell, 1996.

Hillary, Edmund. View from the Summit. Sage, 2000.

Hippies in Nepal: Italki. 1st Jan, 2017. <https://www.italki.com/question/93644>

Hodge, Margaret. "Waterstones today!” Daily Newsletter, London.

Lonely Planet: Nepal. 13th ed., Lonely Planet Publications, 2011.

Mitchell, James A. The Walrus and the Elephants: John Lennon's Years of Revolution. Seven Stories Press, 2013.

Mumford, Lewis. The City in History. Harcourt, Brace and World, 1961.

Pietry, Joe. Summer of Love: Hippie Writers and Latter-Day Beats. Sage, 1980.

Pike, Burton. The Image of the City in Modern Literature. Princeton UP, 1981.

Santana, Carlos. The Universal Tone: My Life. Kindle Books, 2014.

Shakya, Karna. "Kathmandu: Myth or Reality.” The Himalayan Times, 2 Sept 2011.

Storey, John. Cultural Theory and Popular Culture: An Introduction. Pearson Longman, 1989.

Subedi, Abhi Narayan. "Hippies in Nepal Mandala." Six Seasons Review. vol. 2. no. 3 and 4, 2002, pp. 161-75.

The Golden Child. Ritchie Michael. Miramax, 1986.

To the North Of Kathmandu. Wiemer Robert. Paramount Pictures, 1988. 
Urry, John. Tourist Gaze: Leisure and Travel in Contemporary Societies. Sage, 1990.

Woody, Allen. Annie Hall. United Artists, 1977.

Wohl, Richard R. and Anselm L. Strauss. Symbolic Representation and the Urban Milieu. New York Books, 1958.

Witch from Nepal. Siu-tung Ching. Golden Harvest and Paragon Films, 1986.

Zarra, Christiana. Sacred Journeys and Profane Travelers: Representation and Spatial Practicein Varanasi. Diss. University of London, 2011. 